\title{
Worksampling Sebagai Usaha Mengukur Produktivitas Perakitan Kursi Model Praktikum Analisa Perancangan Sistem Kerja Dan Ergonomi
}

\author{
Boy Isma Putra1), Indah Apriliana Sari .W'2), Ribangun Bambang Jakaria ${ }^{3)}$ \\ ${ }^{12) 3)}$ Program Studi Teknik Industri, Universitas Muhammadiyah Sidoarjo \\ E-mail: ${ }^{1}$ boy@umsida.ac.id, ${ }^{2}$ indahapriliana@umsida.ac.id, \\ 3ribangunbz@umsida.ac.id
}

\begin{abstract}
Abstrak
Laboratorium Analisa Perancangan Sistem Kerja dan Ergonomi merupakan salah satu fasilitas yang dimiliki oleh Teknik Industri Universitas Muhammadiyah Sidoarjo. Salah satu kegiatan kerja yang dilakukan di fasilitas ini adalah kegiatan perakitan kursi model. Sebagaimana kita ketahui bersama, bahwa hasil dari setiap kegiatan/ pekerjaan pasti memiliki output, baik itu berupa jasa maupun produk manufaktur. Dalam setiap output yang dikeluarkan memiliki proses-prosesnya sendiri. Dari setiap proses yang ada pasti kita bisa mengamati cara kerja masingmasing proses, apakah termasuk produktif (termasuk dengan tingkat efektif dan efisien tinggi) atau tidak, apakah memiliki idle time atau tidak. Dari hal tersebut, kita bisa mengamati proses kerja menggunakan metode Work Sampling atau dalam bahasa asingnya disebut Ratio Delay Study atau Random Observation Method. Metode ini adalah suatu teknik untuk mengadakan sejumlah besar pengamatan terhadap aktivitas kerja dari mesin, proses, atau pekerja/operator. Permasalahan yang terjadi saat ini adalah belum adanya pengukuran kegiatan kerja pada operator perakitan kursi model selama pandemi covid 19 yang dilakukan pada mahasiswa peserta praktikum. Pada penelitian ini peneliti akan mencari nilai prosentase produktiv, rasio delay dan jumlah menit produktif. Adapun hasil yang didapat pada penelitian ini adalah banyaknya jumlah pengamatan/ kunjungan berdasarkan penentuan satuan waktu sebanyak 23 kali, terdapat 19kegiatan produktif dengan prosentase sebesar sebesar $83 \%$ dan 4 kegiatan non produktif dengan prosentase sebesar $17 \%$. Nilai ratio delay sebesar 0,20 dan jumlah menit produktifnya sebesar 21,64 menit.
\end{abstract}

Kata Kunci: Works sampling, Prosentase Produktif, Rasio Delay, Jumlah Menit Pengamatan

\begin{abstract}
Laboratory of Work System Design Analysis and Ergonomics is one of the facilities owned by Industrial Engineering, University of Muhammadiyah Sidoarjo. One of the work activities carried out at this facility is the assembly of model chairs. As we all know, that the results of every activity/work must have an output, both in the form of services and manufactured products. In each output issued has its own processes. From each existing process, we can certainly observe how each process works, whether it is productive (including with a high level of effectiveness and efficiency) or not, whether it has idle time or not. From this case, we can observe the work process using the Work Sampling method or in a foreign language called Ratio Delay Study or Random Observation Method. This method is a technique for conducting a large number of observations on the work activities of machines, processes, or
\end{abstract}


workers/operators. The problem that occurs at this time is that there is no measurement of work activities on model chair assembly operators during the covid 19 pandemic which is carried out on students participating in practicum. In this study, researchers will look for the percentage of productive, the ratio of delay and the number of productive minutes. The results obtained in this study are the number of observations / visits based on the determination of the time unit as much as 23 times, there are 19 productive activities with a percentage of $83 \%$ and 4 non-productive activities with a percentage of $17 \%$. The delay ratio value is 0.20 and the number of productive minutes is 21.64 minutes.

Keywords: Works sampling, Productive Percentage, Delay Ratio, Number of Minutes of Observation

\section{PENDAHULUAN}

Laboratorium Analisa Perancangan Sistem Kerja dan Ergonomi merupakan salah satu fasilitas yang dimiliki oleh Teknik Industri Universitas Muhammadiyah Sidoarjo. Salah satu kegiatan kerja yang dilakukan di fasilitas ini adalah kegiatan perakitan kursi model. Permasalahan yang terjadi saat ini adalah belum adanya pengukuran kegiatan kerja pada operator perakitan kursi model selama pandemi covid 19 yang dilakukan pada mahasiswa peserta praktikum. [1] Metode yang digunakan dalam penelitian ini adalah metode sampling kerja. Work Sampling atau dalam bahasa asingnya disebut Ratio Delay Study atau Random Observation Method adalah suatu teknik untuk mengadakan sejumlah besar pengamatan terhadap aktivitas kerja dari mesin, proses, atau pekerja/operator [1].

Teknik Work Sampling ini pertama kali digunakan oleh seorang sarjana Inggris bernama L.H.C Tippett dalam aktivitas penelitiannya di industri tekstil. Selanjutnya cara atau metode Work Sampling telah terbukti sangat efektif karena dengan cepat dan mudah cara ini akan dapat dipakai untuk penentuan waktu longgar (allowance time) yang tersedia untuk satu pekerjaan, pendayagunaan mesin yang sebaik-baiknya, dan penetapan waktu baku untuk proses produksi.

Secara garis besar metode Work Sampling ini akan dapat digunakan untuk: a. Mengukur "Ratio Delay"dari sejumlah mesin, karyawan/operator, atau fasilitas kerja lainnya. Sebagai contoh ialah untuk menentukan presentase dari jam atau hari di mana mesin atau orang benar-benar terlibat dalam aktivitas kerja, dan presentase di mana sama sekali tidak ada aktivitas kerja yang dilakukan (idle time). 
b. Menetapkan "Performance Level" dari seseorang selama waktu kerjanya berdasarkan waktu-waktu di mana orang ini bekerja atau tidak bekerja terutama sekali untuk pekerjaan-pekerjaan manual.

c. Menentukan waktu baku untuk suatu proses/operasi kerja seperti halnya yang bisa dilaksanakan oleh pengukuran kerja lainnya.

Metode Work Sampling ini dikembangkan berdasarkan hukum probabilitas, karena itulah maka pengamatan suatu obyek tidak perlu dilaksanakan secara menyeluruh (populasi) melainkan cukup dilakukan dengan menggunakan contoh (sample) yang diambil secara acak dari suatu grup. Suatu contoh/sample yang diambil secara acak dari suatu grup yang besar akan cenderung memiliki pola distribusi yang sama seperti yang dimiliki oleh grup populasi tersebut. Dengan demikian, contoh/sample yang diambil tidak akan jauh berbeda dibandingkan dengan karakteristik grup populasinya.

Banyaknya pengamatan yang harus dilakukan dalam Work Sampling akan dipengaruhi oleh 2 faktor utama, yaitu:

a. Tingkat ketelitian (Degree of Accuracy) dari hasil pengamatan.

b. Tingkat kepercayaan (Level of Confidence) dari hasil pengamatan.

Tujuan dari penelitian ini adalah untuk menentukan besarnya rasio delay pada kegiatan perakitan.

\section{METODE PENELITIAN}

\section{Metode Work Sampling}

Work sampling adalah suatu teknik untuk mengadakan sejumlah besar pengamatan terhadap aktivitas kerja dari pekerja. Pengamatan aktivitas kerja untuk selang waktu yang diambil secara acak terhadap satu atau lebih pekerja dan kemudian mencatatnya apakah pekerja dalam keadaan bekerja atau menganggur. Pengukuran beban kerja tenaga kerja dengan metode work sampling untuk menghitung waktu baku, produksi standar, beban kerja dan jumlah tenaga kerja yang diperlukan [2].

Metode work sampling memiliki akurasi yang lebih, karena data yang diambil secara langsung dilokasi pekerjaan, sehingga faktor-faktor perlakuan yang diukur dapat diketahui secara mendetail. Kedekatan antara peneliti dan pekerja dapat memberikan instruksi-instruksi yang lebih mudah dijalankan oleh karyawan 
serta mengurangi pengambilan data yang kurang sesuai misalnya pekerja melakukan usaha berlebih untuk menyelesaikan satu produk.

\section{Tabel Bilangan Acak}

Untuk melakukan pengamatan dalam sampling kerja maka masing-masing kejadian yang diamati selama aktivitas kerja berlangsung harus memiliki kesempatan yang sama untuk diamati. Dengan kata lain pengamatan haruslah dilaksanakan acak (random). Untuk maksud ini maka penggunaan tabel angka acak (random number tables) barang kali merupakan metode yang terbaik guna menjamin bahwa sampel pengamatan yang diambil benar-benar dipilih secara acak [2].

Bilangan acak adalah deretan nilai yang acak dan tidak dapat diprediksi secara keseluruhan. Untuk menghasilkan bilangan acak merupakan hal yang sulit, kebanyakan pembangkit bilangan acak (Random Number Generator $=$ RNG) mempunyai beberapa bagian yang dapat diprediksi dan berhubungan [3].

\section{Persentase Produktif}

Persentase produktif adalah kegiatan seorang pekerja yang sesuai dengan job desk yang telah ditentukan oleh perusahaan. Segala waktu proses kegiatan tersebut dibagi dengan waktu keseluruhan dalam menyelesaikan pekerjaan disajikan dalam bentuk persentase [4]. Rumus persentase produktif yaitu:

$\overline{\mathrm{p}}=\frac{\sum \text { Produktif }}{\mathrm{n}}$

Keterangan:

$\begin{array}{ll}\overline{\mathrm{p}} & =\text { persentase produktif } \\ \sum_{\mathrm{n}} \text { Produktif } & =\text { jumlah persentase produktif } \\ & =\text { jumlah pengamatan }\end{array}$

\section{RatioDelay}

Pemberian kelonggaran ini dimaksudkan untuk memberi kesempatan kepada operator untuk melakukan hal-hal yang harus dilakukannya, sehingga waktu baku yang diperoleh dapat dikatakan data waktu kerja yang lengkap dan mewakili sistem kerja yang diamati [6]. Rumus ratio delay yaitu: Worksampling Sebagai Usaha Mengukur Produktivitas Perakitan Kursi Model Praktikum Analisa Perancangan Sistem Kerja Dan Ergonomi (Boy Isma Putra, Indah Apriliana Sari .W, Ribangun Bambang Jakaria) 
Ratio delay $=\frac{\text { persentase } \text { non } \text { produktif }}{\text { persentase produktif }}$

\section{JMP (Jumlah Menit Produktif)}

Jumlah menit produktif atau JMP adalah hasil dari perkalian antara persentase produktif dengan jumlah menit pengamatan [4]. RumusJumlah Menit Produktif yaitu:

$\mathrm{JMP}=$ persentase produktif $\mathrm{x}$ jumlah menit pengamatan

Adapun flowchart pada penelitian ini adalah sebagai berikut:

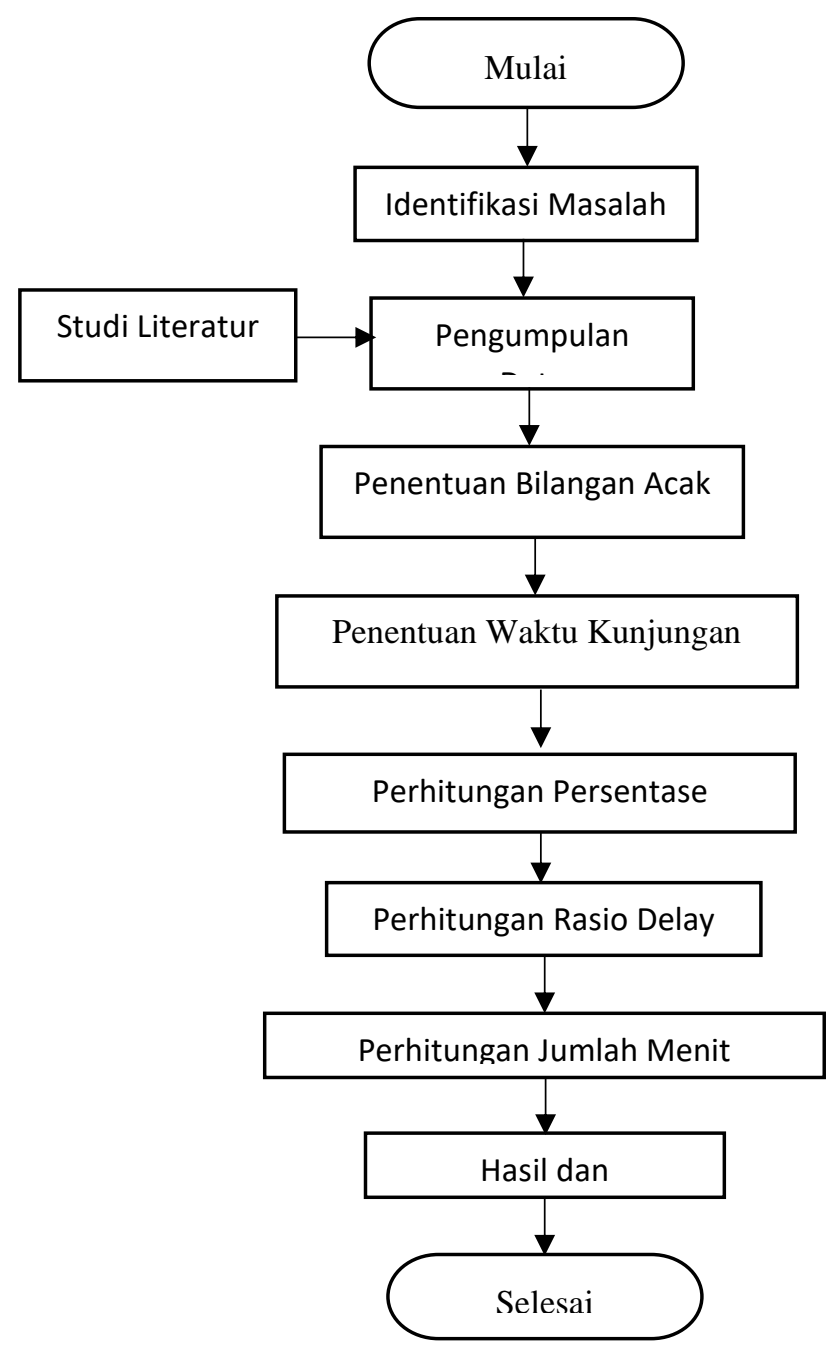




\section{HASIL DAN PEMBAHASAN}

\section{Data Penelitian}

Berikut adalah data yang dikumpulkan oleh praktikan pada saat praktikum.

1. 1 shift $=1 \mathrm{jam}=60$ menit $=3600$ detik

2. 1 kali pengamatan $=68$ detik

3. Menentukan satuan waktu:

Karena waktu yang dibutuhkan untuk 1 kali pengamatan $=68$ detik dan jam kerja selama praktikum adalah 1 jam $=3600$ detik, maka satuan waktu yang dibutuhkan adalah 3600 detik / 68 detik = 53 satuan waktu

4. Tabel bilangan acak

Berikut ini adalah tabel bilangan acak yang yang terlihat pada Tabel 3.1:

Tabel 3.1 Tabel bilangan acak

\begin{tabular}{|l|l|l|l|l|}
\hline 34 & 18 & 04 & 52 & 35 \\
\hline 11 & 20 & 99 & 45 & 18 \\
\hline 27 & 37 & 83 & 28 & 71 \\
\hline 10 & 65 & 81 & 92 & 59 \\
\hline 59 & 71 & 74 & 17 & 32 \\
\hline
\end{tabular}

\begin{tabular}{|l|l|l|l|l|}
\hline 74 & 13 & 39 & 35 & 22 \\
\hline 76 & 51 & 94 & 84 & 86 \\
\hline 79 & 57 & 95 & 13 & 91 \\
\hline 77 & 31 & 61 & 95 & 46 \\
\hline 48 & 38 & 75 & 93 & 29 \\
\hline
\end{tabular}

5. Dari bilangan acak yang terlihat di atas, selanjutnya adalah menghilangkan angka yang sama dan juga hapus angka yang besarnya di atas 53 satuan waktu.

Tabel 3.2 Tabel bilangan acak (diberi warna)

\begin{tabular}{|l|l|l|l|l|}
\hline 34 & 18 & 04 & 52 & 35 \\
\hline 11 & 20 & 99 & 45 & 18 \\
\hline 27 & 37 & 83 & 28 & 71 \\
\hline 10 & 65 & 81 & 92 & 59 \\
\hline 59 & 71 & 74 & 17 & 32 \\
\hline
\end{tabular}

\begin{tabular}{|l|l|l|l|l|}
\hline 74 & 13 & 39 & 35 & 22 \\
\hline 76 & 51 & 94 & 84 & 86 \\
\hline 79 & 57 & 95 & 13 & 91 \\
\hline 77 & 31 & 61 & 95 & 46 \\
\hline 48 & 38 & 75 & 93 & 29 \\
\hline
\end{tabular}

Keterangan: $\square$ = data yang dipakai

Worksampling Sebagai Usaha Mengukur Produktivitas Perakitan Kursi Model Praktikum Analisa Perancangan Sistem Kerja Dan Ergonomi (Boy Isma Putra, Indah Apriliana Sari .W, Ribangun Bambang Jakaria) 
6. Mengurutkan angka

Setelah menghapus angka yang sama serta angka di atas 53, langkah selanjutnya mengurutkan angka dari yang terkecil hingga yang terbesar yang besarnya dibawah 53 satuan waktu, yaitu:

Tabel 3.3 Tabel bilangan setelah dipilih dan diurutkan

\begin{tabular}{|l|l|l|l|l|l|l|l|l|l|l|l|}
\hline 04 & 10 & 11 & 13 & 17 & 18 & 20 & 22 & 27 & 28 & 29 & 31 \\
\hline 32 & 34 & 35 & 37 & 38 & 39 & 45 & 46 & 48 & 51 & 52 & \\
\hline
\end{tabular}

7. Menentukan jam kunjungan kerja

Jam kerja dimulai dari pukul 12.50 sampai pukul 13.50.

\section{Menentukan Jam Kunjungan}

Jam kerja dimulai pukul 12.50 sehingga jam kunjungan dan kegiatan operator dapat dilihat pada Tabel.......dibawah ini:

Tabel 4.1 Jam kunjungan kerja operator serta status operator

\begin{tabular}{|c|c|c|c|}
\hline \multirow{2}{*}{ No. } & \multirow{2}{*}{ Jam kunjungan kerja } & \multicolumn{2}{|c|}{ Status Operator } \\
\cline { 3 - 4 } & & Produktif & Idle \\
\hline 1 & $12.50+(04 / 60 \times 68)=12.54$ & $\mathrm{~V}$ & \\
\hline 2 & $12.50+(10 / 60 \times 68)=13.01$ & $\mathrm{~V}$ & \\
\hline 3 & $12.50+(11 / 60 \times 68)=13.02$ & $\mathrm{~V}$ & \\
\hline 4 & $12.50+(13 / 60 \times 68)=13.05$ & $\mathrm{~V}$ & \\
\hline 5 & $12.50+(17 / 60 \times 68)=13.09$ & $\mathrm{~V}$ & \\
\hline 6 & $12.50+(18 / 60 \times 68)=13.10$ & $\mathrm{~V}$ & \\
\hline 7 & $12.50+(20 / 60 \times 68)=13.13$ & $\mathrm{~V}$ & \\
\hline 8 & $12.50+(22 / 60 \times 68)=13.15$ & $\mathrm{~V}$ & \\
\hline 9 & $12.50+(27 / 60 \times 68)=13.21$ & & V \\
\hline 10 & $12.50+(28 / 60 \times 68)=13.22$ & $\mathrm{~V}$ & \\
\hline 11 & $12.50+(29 / 60 \times 68)=13.23$ & & V \\
\hline
\end{tabular}




\begin{tabular}{|c|c|c|c|}
\hline 12 & $12.50+(31 / 60 \times 68)=13.25$ & $\mathrm{~V}$ & \\
\hline 13 & $12.50+(32 / 60 \times 68)=13.26$ & $\mathrm{~V}$ & \\
\hline 14 & $12.50+(34 / 60 \times 68)=13.28$ & $\mathrm{~V}$ & \\
\hline 15 & $12.50+(35 / 60 \times 68)=13.29$ & & $\mathrm{~V}$ \\
\hline 16 & $12.50+(37 / 60 \times 68)=13.30$ & $\mathrm{~V}$ & \\
\hline 17 & $12.50+(38 / 60 \times 68)=13.33$ & $\mathrm{~V}$ & \\
\hline 18 & $12.50+(39 / 60 \times 68)=13.34$ & & $\mathrm{~V}$ \\
\hline 19 & $12.50+(45 / 60 \times 68)=13.41$ & $\mathrm{~V}$ & \\
\hline 20 & $12.50+(46 / 60 \times 68)=13.42$ & $\mathrm{~V}$ & \\
\hline 21 & $12.50+(48 / 60 \times 68)=13.44$ & $\mathrm{~V}$ & \\
\hline 22 & $12.50+(51 / 60 \times 68)=13.48$ & $\mathrm{~V}$ & \\
\hline 23 & $12.50+(52 / 60 \times 68)=13.49$ & $\mathrm{~V}$ & \\
\hline
\end{tabular}

a. Presentase Non Produktif $(\mathrm{PNP})=\frac{\text { Total Idle }}{\text { Total Pengamatan }} \times 100 \%$

$$
\begin{aligned}
& =\frac{4}{23} \times 100 \% \\
& =0,17=17 \%
\end{aligned}
$$

b. Presentase Produktif (PP) $=\frac{\text { Total Produktif }}{\text { Total Pengamatan }} \times 100 \%$

$$
\begin{aligned}
& =\frac{19}{23} \times 100 \% \\
& =0,83=83 \%
\end{aligned}
$$

c. Ratio Delay

$$
=\frac{\text { Presentase } \text { Non Produktif }}{\text { Presentase Produktif }}
$$$$
=\frac{17}{83}=0,20
$$

d. Jumlah Menit Produktif $=$ PP x JMP

$$
=0,83 \times 26,06=21,64 \text { menit }
$$




\section{KESIMPULAN}

Dari hasil perhitungan penelitian pada kegiatan perakitan kursi model praktikum perancangan sistem kerja dan ergonomi modul work sampling maka didapatkan hasil pengamatan sebanyak $23 \mathrm{kali}$, terdapat 19kegiatan produktif dengan prosentase sebesar sebesar $83 \%$ dan 4 kegiatan non produktif dengan prosentase sebesar $17 \%$. Nilai ratio delay sebesar 0,20 dan jumlah menit produktifnya sebesar 21,64 menit.

\section{DAFTAR PUSTAKA}

[1] S. Wignjosoebroto, Ergonomi Studi Gerak dan Waktu, Surabaya: Guna WIdya, 2006.

[2] Jono, "Pengukuran Beban Kerja Tenaga Kerja dengan Metode Work Sampling," Spektrum Industri, vol. 13, no. 2, pp. 115-228, 2015.

[3] R. D. Tjahjono, A. P. N. and A. A. Widodo, "IMPLEMENTASI UNIQUE CODE NOMINAL TRANSFER MENGGUNAKAN METODE LINEAR CONGRUENTIAL GENERATOR UNTUK ORDER DEPOSIT," Jurnal Informatika Merdeka Pasuruan, vol. 1, no. 3, pp. 39-52, 2016.

[4] Hermanto, "ANALISIS PRODUKTIVITAS PEKERJA DI LANTAI PRODUKSI PADA PT. XACTI DEPOK JAWA BARAT DENGAN MENGGUNAKAN METODE WORK SAMPLING," Jurnal Teknik, vol. 4, no. 1, pp. 1-9, 2015.

[5] R. Yasra and M. Sahril, "PENETAPAN WAKTU STANDAR OPERATOR PELAYANAN PENGISIAN BBM DENGAN MENGGUNAKAN METODE WORK SAMPLING. (STUDI KASUS DI PT. PERTAMINA RETAIL SPBU COCO SEILADI BATAM)," Jurnal Industri Kreatif, vol. 3, no. 1, pp. 79-88, 2019.

[6] H. R. Zadry, L. Susanti, B. Yuliandra and D. Jumeno, ANALISIS DAN PERANCANGAN SISTEM KERJA, Padang: Andalas University Press, 2015.

[7] E. G. Santoso and J. Raharjo, "Standarisasi, Monitoring, dan Compliance Kebersihan dan K3," Jurnal Tirta, vol. 4, no. 1, pp. 115-120, 2016. 